\author{
RESEARCHPAPER
}

\title{
Erodibility status of soils under different land uses in Chiephobozou sub-division soils of Kohima, Nagaland
}

\author{
MANOJ DUTTA, RUOPFIINUO MEZHII, RIZONGBA KICHU AND SEWAK RAM \\ Department of Soil and Water Conservation, School of Agricultural Sciences and Rural Development, Nagaland \\ University, Medziphema Campus, MEDZIPHEMA (NAGALAND) INDIA \\ Email : manojdutta1997@yahoo.com; mercymez30@gmail.com; rizongba09@gmail.com; sewaksasrd@gamil.com
}

Article Info : Received : 30.07.2017; Revised : 24.08.2017; Accepted : 22.09.2017

Land use effect on soil erodibility parameters were studied in four villages, viz., Tsiesema, Riisoma, Chiephobozou and Botsa in Kohima district, Nagaland, under four land uses, viz., orchard, shifting cultivation, lowland and forest in each village. The mean textural classes of the soils were clay, clay loam and sandy clay loam. Dispersion ratio and erosion index were recorded to be usually higher than the threshold limits. Dispersion ratio of the soils ranged from 8.16 to 30.53 whereas, erosion index varied between 5.28 and 23.91. A significant negative correlation of clay with dispersion ratio and erosion index was observed. The highly significant and positive correlation between erosion index and dispersion ratio indicated the susceptibility of these soils to water erosion. Proper agronomic and mechanical soil and water conservation measures need to be adopted to protect the soils from further degradation.

Key words : Land uses, Dispersion ratio, Erosion index

How to cite this paper : Dutta, Manoj, Mezhii, Ruopfiinuo, Kichu, Rizongba and Ram, Sewak (2017). Erodibility status of soils under different land uses in Chiephobozou sub-division soils of Kohima, Nagaland. Asian J. Bio. Sci., 12 (2) : 248-253.DOI : 10.15740/HAS/AJBS/ 12.2/248-253. 